\title{
A Clinical Study Of Segmental Mandibulectomy For Medication-Related Osteonecrosis Of The Jaw
}

\author{
Mitsunobu Otsuru ( $\sim$ ootsuru@nagasaki-u.ac.jp) \\ Nagasaki University https://orcid.org/0000-0002-2173-536X \\ Sakiko Soutome \\ Nagasaki University Hospital: Nagasaki Daigaku Byoin \\ Saki Hayashida \\ Nagasaki University Hospital: Nagasaki Daigaku Byoin \\ Satoshi Rokutanda \\ Nagasaki University Hospital: Nagasaki Daigaku Byoin \\ Souichi Yanamoto \\ Nagasaki University Hospital: Nagasaki Daigaku Byoin \\ Masahiro Umeda \\ Nagasaki University Hospital: Nagasaki Daigaku Byoin
}

\section{Research Article}

Keywords: osteonecrosis, segmental mandibulectomy, treatment outcome, terminal care, bone modifying agents, oral feeding

Posted Date: June 25th, 2021

DOI: https://doi.org/10.21203/rs.3.rs-589903/v1

License: (c) (i) This work is licensed under a Creative Commons Attribution 4.0 International License. Read Full License 


\section{Abstract \\ Purpose}

Few studies have focused on segmental mandibulectomy for the surgical treatment of patients with medication-related osteonecrosis of the jaw (MRONJ). The purpose of this retrospective study was to investigate the extent of mandibular resection required and the treatment outcomes.

\section{Methods}

One hundred thirty-seven patients with MRONJ who underwent surgical treatment at the Nagasaki University Hospital between 2011 and 2019 were included in the study. A total of 168 surgeries (155 marginal mandibulectomies; 13 segmental mandibulectomies) were performed. The relationship between various clinical and imaging factors and the treatment outcomes were investigated in the 13 cases of segmental mandibulectomy.

\section{Results}

Preoperative computed tomography revealed osteolytic lesions (13/13), periosteal reaction (PR; 12/13), and osteosclerosis (12/13) in patients who underwent segmental mandibulectomies. Postoperative CT revealed no residual osteolytic lesions and PR, although osteosclerosis persisted in nine patients. The cure rate of segmental mandibulectomy was $92.3 \%$ (12/13), whereas that of marginal mandibulectomy was $67.1 \%(104 / 155)$. One patient relapsed after segmental mandibulectomy was cured by additional resection. Two and four patients received reconstruction with free fibula flap and reconstruction metal plate, respectively; seven patients did not undergo reconstructive surgery in consideration of their poor general condition or will. Finally, in all the 13 patients, clinical symptoms such as pain and purulent discharge disappeared and oral intake was possible.

\section{Conclusion}

Considering the end-of-life care, segmental mandibulectomy is a treatment option for refractory MRONJ, because it can eliminate clinical symptoms early. When segmental mandibulectomy is performed, the area involving osteolytic lesions and PR must be included.

\section{Introduction}

Bone modifying agents (BMA), such as bisphosphonate (BP) and denosumab (Dmab), are used as first-line agents to prevent osteoporosis-related fractures and to treat skeletal-related events in malignancies [1]. These drugs have a strong inhibitory effect on bone resorption, but can cause medication-related osteonecrosis of the jaw (MRONJ) as a serious late adverse event. MRONJ may cause excruciating suffering, such as pathologic fractures, fistula formation, chronic pain, and infection. The causes and treatment of MRONJ remain unclear. Conservative treatment has been recommended as the first-line treatment, but surgical treatment is also an option when conservative treatment fails to achieve favorable results[1, 2]. There are few reports on segmental mandibulectomy of mandibular MRONJ [3]. However, whether segmental mandibulectomy is an excessive treatment for MRONJ remains a matter of investigation. The purpose of this study was to examine the effectiveness of segmental mandibulectomy in patients with MRONJ of the lower jaw in terms of the treatment outcomes.

\section{Materials And Methods}

\section{Patients}

A total of 137 patients with MRONJ of the lower jaw who underwent surgical treatment at the Nagasaki University Hospital between 2011 and 2019 were included in the study. We identified a total of 168 surgeries comprising 155 marginal mandibulectomies and 13 segmental mandibulectomies. Sixteen patients underwent two to three mandibulectomies and eight patients underwent one to two mandibulectomies followed by mandibular segmental resection. Although the number segmental and marginal mandibulectomies, performed as the first operation, should be compared, because segmental mandibulectomies are often performed in patients with poor prognosis of marginal mandibulectomies, the total numbers of each operation were compared.

\section{Methods}

We examined patient data comprising the age, sex, primary disease, type of BMA, administration period of a BMA, corticosteroid administration, presence of diabetes, stage of MRONJ, surgical method, and treatment outcomes.

For patients who underwent segmental mandibulectomy, we evaluated the duration from the first visit to surgery (days); presence of inferior alveolar nerve palsy, cutaneous fistula, and pathological fracture; and dietary form before surgery and after discharge. Osteolytic lesions, periosteal reaction (PR), osteosclerosis, thickening of the cortical bone of the mandible (TCB), and thickening of the mandibular canal wall (TCW) were also examined using pre- and postoperative computed tomography (CT). TCB and TCW were considered positive if they were enlarged when compared to the opposite side. Interpretation of CT images was performed by an oral surgeon blinded to the clinical course.

\section{Statistical analysis}

All statistical analyses were performed using SPSS software (version 24.0; Japan IBM Co., Ltd., Tokyo, Japan). The correlation between each variable and the surgical method was analyzed using the Mann-Whitney $U$ test for continuous variables and the Fisher's exact test for categorical variables. A two-tailed 
probability of less than 0.05 was considered significant.

\section{Ethics}

We have read the Helsinki Declaration and have followed its guidelines in this investigation. This study was approved by the Institutional Review Board of the Nagasaki University Hospital (\#21021509). The research protocol and the guaranteed opportunity to opt-out were made available on the hospital's official website. The study was not registered as this was a retrospective observational study.

\section{Results}

The demographic characteristics of the 137 patients are summarized in Table 1. There were 104 women and 33 men (median age: 79 years). The primary disease was osteoporosis in 87 patients and malignant tumors in 50 patients. The initial surgical method was marginal mandibulectomy in 132 patients and segmental mandibulectomy in 5 patients. The final cure rate was $81.0 \%(111 / 137)$, including cases with multiple surgeries.

Table 1

Demographic factors of 137 patients with mandibular MRONJ undergoing surgery

\begin{tabular}{|c|c|c|}
\hline Factor & Category & Number of patients / Median (minimum-maximum) \\
\hline Age (years) & & $79(47-95)$ \\
\hline \multirow[t]{2}{*}{ Sex } & male & 33 \\
\hline & female & 104 \\
\hline \multirow[t]{2}{*}{ Primary disease } & osteoporosis & 87 \\
\hline & malignant tumor & 50 \\
\hline \multirow[t]{2}{*}{ Type of BMA } & $\mathrm{BP}$ & 91 \\
\hline & Dmab & 46 \\
\hline \multirow[t]{3}{*}{ Administration period of $\mathrm{BMA}$} & $\geqq 4$ years & 74 \\
\hline & $<4$ years & 56 \\
\hline & unknown & 7 \\
\hline \multirow[t]{2}{*}{ Corticosteroid } & - & 107 \\
\hline & + & 30 \\
\hline \multirow[t]{2}{*}{ Diabetes } & - & 117 \\
\hline & + & 20 \\
\hline \multirow[t]{3}{*}{ MRONJ Stage } & stage 1 & 1 \\
\hline & stage 2 & 101 \\
\hline & stage 3 & 35 \\
\hline \multirow[t]{2}{*}{ Initial surgery } & marginal mandibulectomy & 132 \\
\hline & segmental mandibulectomy & 5 \\
\hline \multirow[t]{2}{*}{ Treatment outcome } & healing & 111 \\
\hline & non-healing & 26 \\
\hline
\end{tabular}

A total of 168 surgeries comprising 155 marginal mandibulectomies and 13 segmental mandibulectomies were performed. As opposed to marginal mandibulectomy, segmental mandibulectomy was indicated in patients with a more advanced stage of MRONJ. The cure rate of segmental mandibulectomy was $92.3 \%$ (12/13), whereas that of marginal mandibulectomy was $67.1 \%(104 / 155)$ (Table 2). 
Table 2

Univariate analysis comparing marginal mandibulectomy and segmental mandibulectomy $(\mathrm{N}=168)$

\begin{tabular}{|c|c|c|c|c|}
\hline & & \multirow[t]{2}{*}{ marginal mandibulectomy $(\mathrm{N}=155)$} & \multirow[t]{2}{*}{ segmental mandibulectomy $(\mathrm{N}=13)$} & \multirow[b]{2}{*}{$P$} \\
\hline & & & & \\
\hline Age(Years) & & $47-95(78)$ & $48-91(79)$ & 0.912 \\
\hline \multirow[t]{2}{*}{ Sex } & male & 40 & 5 & 0.322 \\
\hline & female & 115 & 8 & \\
\hline \multirow[t]{2}{*}{ Primary disease } & malignant tumor & 62 & 7 & 0.330 \\
\hline & osteoporosis & 93 & 6 & \\
\hline \multirow[t]{2}{*}{ Type of BMA } & $\mathrm{BP}$ & 102 & 8 & 0.756 \\
\hline & Dmab & 53 & 5 & \\
\hline \multirow[t]{3}{*}{ Administration period of BMA } & $\geqq 4$ years & 62 & 3 & 0.478 \\
\hline & $<4$ years & 85 & 9 & \\
\hline & unknown & 8 & 1 & \\
\hline \multirow[t]{2}{*}{ Corticosteroid } & - & 119 & 10 & 0.990 \\
\hline & + & 36 & 3 & \\
\hline \multirow[t]{2}{*}{ Diabetes } & - & 128 & 10 & 0.609 \\
\hline & + & 27 & 3 & \\
\hline \multirow[t]{3}{*}{ MRONJ Stage } & stage 1 & 1 & 0 & 0.019 \\
\hline & stage 2 & 115 & 5 & \\
\hline & stage 3 & 39 & 8 & \\
\hline \multirow[t]{2}{*}{ Treatment outcome } & Healing & 104 & 12 & 0.059 \\
\hline & Non-Healing & 51 & 1 & \\
\hline
\end{tabular}

A non-healing case that underwent segmental mandibulectomy was noted: A 67-year-old man, with a history of prostate cancer bone metastasis, relapsed after segmental mandibulectomy. He was initially referred to our hospital for cellulitis of the neck caused by mandibular MRONJ. CT revealed extended osteolysis and osteosclerosis. After eliminating the inflammation by drainage surgery, the patient underwent segmental mandibulectomy. Postoperative CT revealed that the cortical bone around the extraction socket remained; 8 months later, MRONJ recurred in this bone, resulting in additional resection. Eighteen months after the last surgery, there was no recurrence of MRONJ.

Of the 13 patients who underwent segmental mandibular osteotomy, only two did so as initial treatment. Furthermore, although conservative therapy was selected as the initial treatment, segmental mandibulectomy was performed due to poor outcomes in three cases. Marginal mandibulectomy was also performed as an initial treatment; however, segmental mandibulectomies were performed later due to recurrence of symptoms in eight cases. The time from the first visit to surgery in the 13 patients who underwent segmental mandibulectomy ranged from 17 to 938 days (median, 246 days). Inferior alveolar nerve palsy (8/13), cutaneous fistula (8/13), and pathological fractures (3/13) were observed. (Table 3). Preoperative CT revealed osteolytic lesions, PR, osteosclerosis, TCB, and TCW in 13,10, 12, 8, and 11 patients, respectively. (Fig. 1) (Table 4) During postoperative CT, we did not observe any residual osteolytic lesions or PR. However, two, four, and nine patients with TCBs, TCWs, and osteosclerosis, respectively, remained. (Fig. 2) (Table 4) Among the 13 patients who underwent segmental mandibulectomy, the dietary patterns before and after surgery worsened from solid to paste and from paste to liquid in four and one patients, respectively, but improved from paste to solid and from liquid to paste in two and one patients, respectively. Malocclusion worsened dietary patterns in some cases, but improved the patterns in others due to pain relief from surgery (Table 3). 
Table 3

Summary of patients who underwent segmental mandibulectomy (Clinical findings)

\begin{tabular}{|c|c|c|c|c|c|c|c|c|c|c|c|c|c|}
\hline No. & Age & Sex & Stage & $\begin{array}{l}\text { Primary } \\
\text { disease }\end{array}$ & $\begin{array}{l}\text { Treatment } \\
\text { outcome }\end{array}$ & $\begin{array}{l}\text { Resection } \\
\text { area }\end{array}$ & $\begin{array}{l}\text { Duration } \\
\text { from the } \\
\text { first visit } \\
\text { to } \\
\text { surgery } \\
\text { (days) }\end{array}$ & $\begin{array}{l}\text { dietary } \\
\text { form } \\
\text { before } \\
\text { surgery }\end{array}$ & $\begin{array}{l}\text { dietary } \\
\text { form } \\
\text { after } \\
\text { surgery }\end{array}$ & $\begin{array}{l}\text { Inferior } \\
\text { alveolar } \\
\text { nerve } \\
\text { palsy }\end{array}$ & $\begin{array}{l}\text { Cutaneous } \\
\text { fistula }\end{array}$ & $\begin{array}{l}\text { Pathological } \\
\text { fracture }\end{array}$ & Reconstn \\
\hline 1 & 84 & female & 2 & 0 & healing & molar & 17 & solid & paste & + & + & - & - \\
\hline 2 & 67 & male & 3 & MT & $\begin{array}{l}\text { non- } \\
\text { healing }\end{array}$ & molar & 28 & solid & paste & - & + & - & - \\
\hline 3 & 78 & female & 3 & 0 & healing & molar & 62 & paste & paste & + & - & - & $\begin{array}{l}\text { reconstru } \\
\text { plate }\end{array}$ \\
\hline 4 & 50 & female & 2 & MT & healing & molar & 938 & solid & paste & + & - & - & fibula \\
\hline 5 & 81 & male & 3 & MT & healing & molar & 495 & paste & solid & - & - & - & - \\
\hline 6 & 84 & female & 2 & 0 & healing & $\begin{array}{l}\text { molar, } \\
\text { front } \\
\text { tooth }\end{array}$ & 110 & paste & liquid & + & - & - & $\begin{array}{l}\text { reconstru } \\
\text { plate }\end{array}$ \\
\hline 7 & 51 & female & 2 & MT & healing & $\begin{array}{l}\text { molar, } \\
\text { front } \\
\text { tooth }\end{array}$ & 853 & solid & solid & + & + & + & $\begin{array}{l}\text { reconstru } \\
\text { plate }\end{array}$ \\
\hline 8 & 83 & male & 3 & MT & healing & molar & 374 & paste & paste & + & + & - & - \\
\hline 9 & 48 & female & 3 & MT & healing & $\begin{array}{l}\text { molar, } \\
\text { front } \\
\text { tooth }\end{array}$ & 208 & paste & paste & - & + & - & fibula \\
\hline 10 & 77 & female & 3 & 0 & healing & molar & 246 & paste & solid & + & + & + & - \\
\hline 11 & 89 & male & 3 & 0 & healing & molar & 283 & solid & paste & - & + & - & - \\
\hline 12 & 91 & female & 2 & 0 & healing & molar & 143 & paste & paste & + & + & + & - \\
\hline 13 & 79 & male & 3 & MT & healing & $\begin{array}{l}\text { molar, } \\
\text { front } \\
\text { tooth }\end{array}$ & 319 & liquid & paste & - & - & - & $\begin{array}{l}\text { reconstru } \\
\text { plate }\end{array}$ \\
\hline
\end{tabular}

Table 4

Summary of patients who underwent segmental mandibulectomy (CT findings)

\begin{tabular}{|c|c|c|c|c|c|c|c|c|c|c|}
\hline \multirow[t]{2}{*}{ No. } & \multicolumn{5}{|c|}{ CT findings before surgery } & \multicolumn{5}{|c|}{ CT findings after surgery } \\
\hline & Osteolytic lesion & PR & Osteosclerosis & TCB & TCW & Osteolytic lesion & PR & Osteosclerosis & ТСВ & TCW \\
\hline 1 & + & + & + & + & + & - & - & + & + & - \\
\hline 2 & + & - & + & - & + & - & - & + & - & + \\
\hline 3 & + & + & + & + & + & - & - & + & - & - \\
\hline 4 & + & + & + & + & + & - & - & + & - & - \\
\hline 5 & + & + & + & - & + & - & - & - & - & - \\
\hline 6 & + & + & + & + & + & - & - & + & - & - \\
\hline 7 & + & + & + & - & - & - & - & + & - & - \\
\hline 8 & + & + & + & + & + & - & - & + & + & + \\
\hline 9 & + & + & + & + & + & - & - & - & - & - \\
\hline 10 & + & - & + & + & + & - & - & - & - & - \\
\hline 11 & + & + & + & + & + & - & - & + & - & + \\
\hline 12 & + & - & + & - & + & - & - & + & - & + \\
\hline 13 & + & + & - & - & - & - & - & - & - & - \\
\hline
\end{tabular}

Reconstruction was performed in six cases to prevent deterioration of respiratory status and facial appearance. Free fibula flap transplantation was performed in two cases, and reconstruction with a metal plate was performed in four cases. The other patients did not undergo reconstructive surgery because of old age, 
poor general condition, or their own will. Furthermore, only one of the reconstructed cases showed improvement in dietary patterns, and reconstruction itself did not necessarily improve dietary habits (Table 3).

\section{Discussion}

The Position Paper of the American Association of Oral and Maxillofacial Surgeons and the Guidelines of Multinational Association of Supportive Care in Cancer/International Society of Oral Oncology (MASCC/ISOO) state that conservative therapies, such as administration of antibiotics and gargling with antiseptic mouthwash, are the first choice of treatments for MRONJ [1, 2]. Surgical therapy can be performed for refractory cases. Conversely, many investigators have reported the superiority of surgical therapy over conservative therapy [4-6]. In a multi-center observational study using propensity score matching analysis, we previously reported that the treatment outcomes were significantly better in patients undergoing surgery than in those undergoing conservative therapy [7].

The quality of life (QOL) of patients with MRONJ decreases as the MRONJ stage progresses [8]. The prognosis for life may not be very long, because many MRONJ patients are elderly or have cancer with distant metastases. Therefore, when choosing a treatment for MRONJ, it is necessary to consider the cure of the disease and the QOL of patients. Persistent pain and pus discharge during the remaining survival period can be very distressing for the patient. We believe that "terminal care" for MRONJ patients, which aims to maintain and improve the QOL by relieving the patients' physical and mental pain, is necessary to choose the treatment method. For this reason, segmental mandibulectomy should be included as an option in the treatment of elderly patients and cancerbearing patients, as it is more likely to be curative.

Hanasono et al. reported no recurrence in 13 patients with MRONJ who underwent segmental mandibulectomy and free flap reconstruction [3]. In the current study, we focused on segmental mandibulectomy for MRONJ. The results showed that the healing rate was higher in segmental mandibulectomy than in marginal mandibulectomy. There was only one recurrence in which the cortical bone of the extraction socket of a tooth was left behind. That patient was cured by additional resection. Of course, because segmental mandibulectomy is highly invasive, marginal mandibulectomy should be performed if the lesion can be controlled. However, conservative therapy and marginal mandibulectomy were performed for more than a year without cure; segmental mandibulectomy was eventually performed in some cases. Therefore, it is necessary to consider the indications for conservative therapy and marginal mandibulectomy.

Bone reconstruction is generally performed because segmental mandibulectomy breaks the continuity of the mandible, resulting in facial deformity and malocclusion. Of the 13 segmental mandibulectomy cases in this study, free fibula flaps and reconstruction plates were transplanted in two and four cases involving the anterior part of the mandible, respectively. Reconstruction was not performed in the remaining seven cases involving the posterior part of the mandible after consultation with the patient, because reconstructive surgery increases the surgical invasion and poses a risk of postoperative infection and reoperation. If bone reconstruction is not performed, malocclusion may lead to masticatory disturbance. In this study, some patients had a worse diet after surgery than before surgery. However, others had a better diet postoperatively than before surgery, and all patients could eat after surgery. The improvement in feeding status despite segmental resection may be due to the relief from symptoms such as pain. As mentioned above, we believe that segmental mandibulectomy is a treatment option for patients with intolerable physical and mental pain or persistent discomfort due to pus discharge despite conservative therapy or marginal mandibulectomy.

The resection range for segmental mandibulectomy was also examined. Marx et al. recommend performing resection until some bone marrow remains, bone color is normal, and bleeding is noted [9]. Nocini et al. reviewed the pathological characteristics of patients who underwent segmental mandibulectomy and found that only one patient had a residual lesion in the resection specimen. The patient experienced a recurrence of MRONJ within 6 months [10]. Similarly, Bedogni et al. analyzed 32 jaws resected for MRONJ and reported that the presence of osteomyelitis at the pathological resection edge was a strong predictor of BRONJ recurrence [11]. However, this is only a diagnosis of pathological specimens and intraoperative findings, and not a preoperative diagnosis. We examined factors for preoperatively assuming the resection range of segmental mandibulectomy. We examined osteolytic lesions, PR, osteosclerosis, TCB, and TCW. Osteolytic lesions and PR can be adequately removed by segmental mandibulectomy. Soutome et al. reported that PR should also be considered when determining the extent of osteotomy [12]. Segmental mandibulectomy seemed more likely to eliminate osteolytic lesions and PR as compared to marginal mandibulectomy.

The osteosclerotic lesion remained in nine cases, but it was not always necessary to include osteosclerosis in the resection field because healing was obtained. We also hypothesized that enlargement of the cortical bone is involved in blood flow disorder when considering blood flow from the periosteal and inferior alveolar arteries. However, there is no apparent relationship between the residual TCB of TCW and the cure rate. Finally, we believe that it is necessary to resect osteolytic lesions and PR when performing segmental mandibulectomy for MRONJ of the mandible.

This study has some limitations. First, this is a retrospective case series of a small number of patients; therefore, it is difficult to generalize the results. Second, because we did not conduct a detailed study of QOL, it was not possible to clarify whether segmental mandibulectomy contributed to improving the patient's QOL. In the future, we would like to examine the decision on the indication for segmental mandibulectomy and verify its effectiveness in a larger number of cases.

\section{Declarations}

\section{Funding}

This research did not receive any specific grant from funding agencies in the public, commercial, or not-for-profit sectors. 


\section{Conflicts of interest}

The authors have no relevant financial or non-financial interests to disclose.

\section{Availability of data and material}

All data generated or analyzed during this study are included in this published article.

\section{Code availability}

Not applicable.

\section{Author contributions}

All authors contributed to the study conception and design. Material preparation, data collection and analysis were performed by Sakiko Soutome, Saki Hayashida , Satoshi Rokutanda, Souichi Yanamoto and Masahiro Umeda and [full name]. The first draft of the manuscript was written by Mitsunobu Otsuru and all authors commented on previous versions of the manuscript. All authors read and approved the final manuscript.

\section{Ethical approval}

This retrospective chart review study involving human participants was in accordance with the ethical standards of the institutional and national research committee and with the 1964 Helsinki Declaration and its later amendments or comparable ethical standards. The Human Investigation Committee (IRB) of Nagasaki University approved this study (\#21021509).

\section{Consent to participate}

Patients were provided an opportunity to withdraw from the study via computer announcement.

\section{Consent for publication}

Not applicable.

\section{Acknowledgements}

The authors are deeply grateful to Misa Sumi (Department of Radiology and Biomedical Informatics, Nagasaki University Graduate School of Biomedical Sciences) for her contributions to the diagnosis and discussion in this study.

\section{References}

1. Yarom N, Shapiro CL, Peterson DE et al (2019) Medication-related osteonecrosis of the jaw: MASCC/ISOO/ASCO clinical practice guideline. J Clin Oncol 37:2270-2290. https://doi.org/10.1200/JC0.19.01186

2. Ruggiero SL, Dodson TB, Fantasia J, Goodday R, Aghaloo T, Mehrotra B, O'Ryan F (2014) American association of oral and maxillofacial surgeons position paper on medication-related osteonecrosis of the jaw-2014 update. J Oral Maxillofac Surg 72:1938-1956. https://doi.org/10.1016/j.joms.2014.04.031

3. Hanasono MM, Militsakh ON, Richmon JD, Rosenthal EL, Wax MK (2013) Mandibulectomy and free flap reconstruction for bisphosphonate-related osteonecrosis of the jaws. JAMA Otolaryngol Head Neck Surg 139:1135-1142. https://doi.org/10.1001/jamaoto.2013.4474

4. Rupel K, Ottaviani G, Gobbo M et al (2014) A systematic review of therapeutical approaches in bisphosphonates-related osteonecrosis of the jaw (BRONJ). Oral Oncol 50:1049-1057. https://doi.org/10.1016/j.oraloncology.2014.08.016

5. Fliefel R, Tröltzsch M, Kühnisch J, Ehrenfeld M, Otto S (2015) Treatment strategies and outcomes of bisphosphonate-related osteonecrosis of the jaw (BRONJ) with characterization of patients: a systematic review. Int J Oral Maxillofac Surg 44:568-585. https://doi.org/10.1016/j.ijom.2015.01.026

6. Khan AA, Morrison A, Hanley DA et al (2015) Diagnosis and management of osteonecrosis of the jaw: a systematic review and international consensus. J Bone Miner Res 30:3-23. https://doi.org/10.1002/jbmr.2405

7. Hayashida S, Soutome S, Yanamoto S et al (2017) Evaluation of the treatment strategies for medication-related osteonecrosis of the jaws (MRONJ) and the factors affecting treatment outcome: a multicenter retrospective study with propensity score matching analysis. J Bone Miner Res 32:2022-2029. https://doi.org/10.1002/jbmr.3191

8. Miksad RA, Lai KC, Dodson TB et al (2011) Quality of life implications of bisphosphonate-associated osteonecrosis of the jaw. Oncologist 16:121-132. https://doi.org/10.1634/theoncologist.2010-0183

9. Marx RE (2009) Reconstruction of defects caused by bisphosphonate-induced osteonecrosis of the jaws. J Oral Maxillofac Surg 67:107-119. https://doi.org/10.1016/j.joms.2008.12.007

10. Nocini PF, Saia G, Bettini G, Ragazzo M, Blandamura S, Chiarini L, Bedogni A (2009) Vascularized fibula flap reconstruction of the mandible in bisphosphonate-related osteonecrosis. Eur J Surg Oncol 35:373-379. https://doi.org/10.1016/j.ejso.2008.05.002

11. Bedogni A, Saia G, Bettini G et al (2011) Long-term outcomes of surgical resection of the jaws in cancer patients with bisphosphonate-related osteonecrosis. Oral Oncol 47:420-424. https://doi.org/10.1016/j.oraloncology.2011.02.024 
12. Soutome S, Yanamoto S, Sumi M et al (2021) Effect of periosteal reaction in medication-related osteonecrosis of the jaw on treatment outcome after surgery. J Bone Miner Metab 39:302-310. https://doi.org/10.1007/s00774-020-01154-6

\section{Figures}

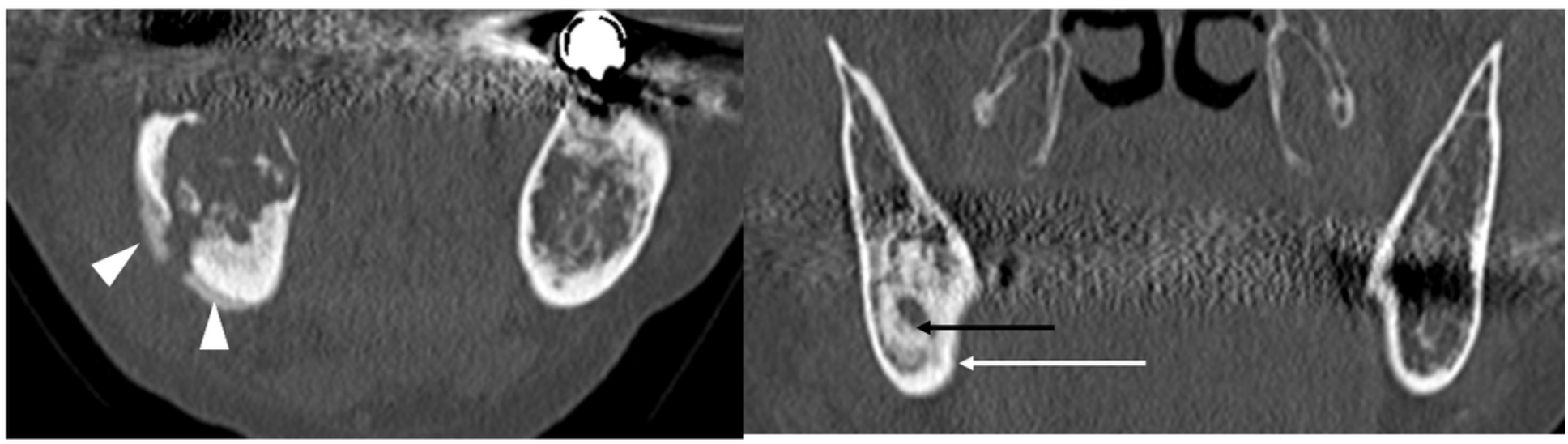

\section{Figure 1}

A: Case 1: Preoperative CT (coronal) reveals extensive osteolytic lesion and PR (white arrow head) and osteosclerosis in the right mandible. B: Case 3: Preoperative CT (coronal) reveals thickening of the cortical bone of the mandible (white arrow) and thickening of the mandibular canal wall (black arrow) 


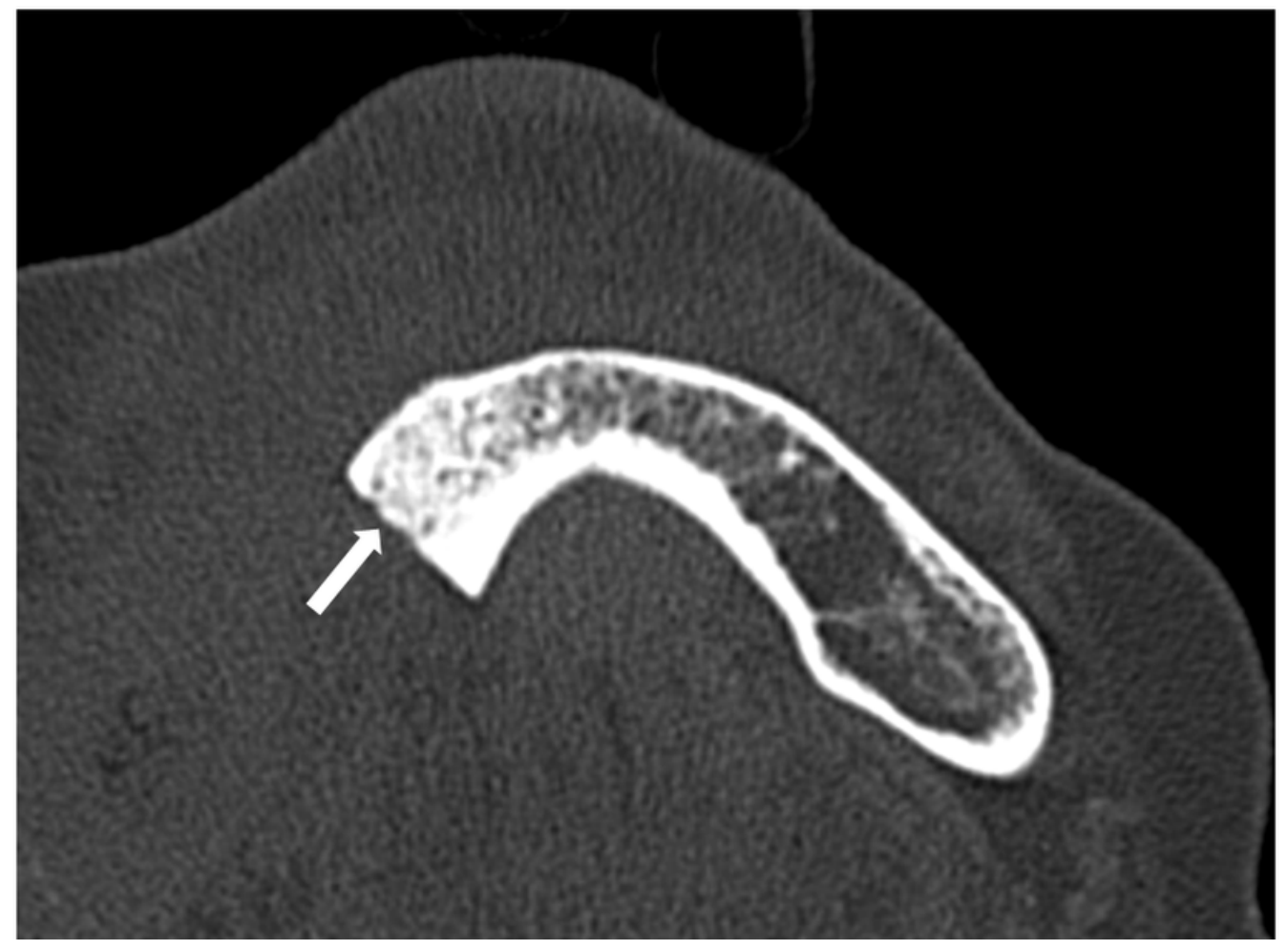

Figure 2

Case 4: Postoperative CT (axial) reveals residual osteosclerosis at the margins of the segmental mandibulectomy (white arrow) 